\title{
Tamoxifen retinopathy: a rare but serious complication
}

\author{
Christopher R Bentley, Geraint Davies, Wagih A Aclimandos
}

\section{Patients taking tamoxifen who complain of visual problems should be assessed carefully and referred early for ophthalmological opinion}

Tamoxifen citrate is a non-steroidal antioestrogen used in the management of selected patients with breast carcinoma. ' The drug has been generally free of serious side effects, though ocular toxicity has been reported in patients treated with high doses ${ }^{23}$ and, more recently, low doses. ${ }^{47}$ We report a case in which toxicity was encountered in an elderly diabetic woman and was initially unrecognised as early retinal changes were attributed to diabetic retinopathy and drusen.

\section{Case report}

In 1985 a 72 year old white woman underwent excision biopsy for an infiltrating duct carcinoma of the left breast and axillary node sampling (all nodes negative). This was followed by a course of radiotherapy and she was started on tamoxifen $40 \mathrm{mg}$ daily. No other chemotherapeutic agents were used. In early 1986 after a short febrile illness she was diagnosed as having non-insulin dependent diabetes mellitus, which responded to glibenclamide $10 \mathrm{mg}$ daily and dietary control.

At review one month later she complained of blurred vision. Her visual acuity was $6 / 9$ right and left. The fundi were described as normal with drusen present.

In April 1987 drusen and hard exudates were noted. In 1989 she was referred to the diabetic eye clinic. Visual acuity was $6 / 18$ right and $6 / 36$ left. Nine months later visual acuity was found to be reduced to $6 /$ 36 right and counting fingers left.

At this stage the original diagnosis of diabetic maculopathy was questioned because of the appearance of superficial yellow crystalline ring-like deposits at both maculae (fig 1). Fluorescein angiography showed bilateral paramacular rings of hyperfluorescence due to superficial staining, which increased throughout the run (fig 2). There was no significant leakage and no changes typical of diabetic retinopathy were found. The central visual fields were noticeably suppressed and colour vision (determined with ishihara plates) was considerably reduced in both eyes. Results of electrophysiological tests were within normal limits. These changes are similar to those described in previous reports of tamoxifen retinal toxicity. ${ }^{2378}$ Tamoxifen

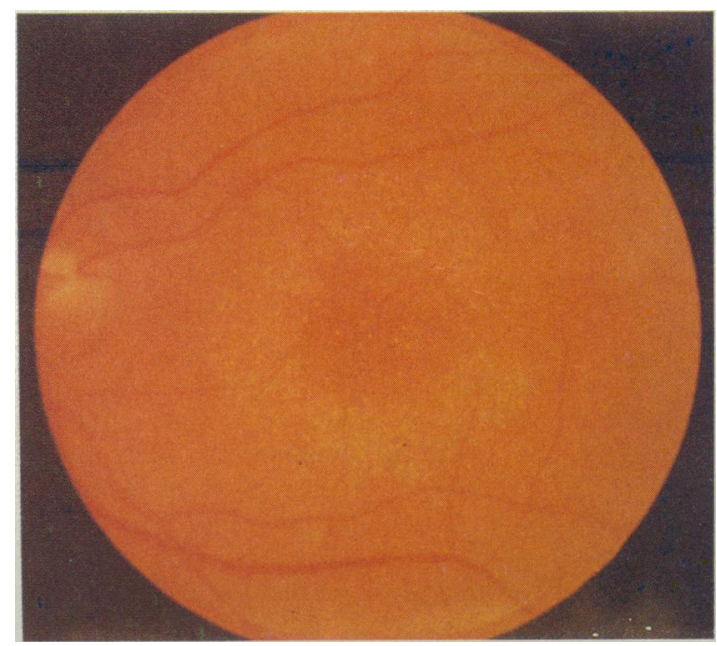

FIG 1-Crystalline deposits at macula

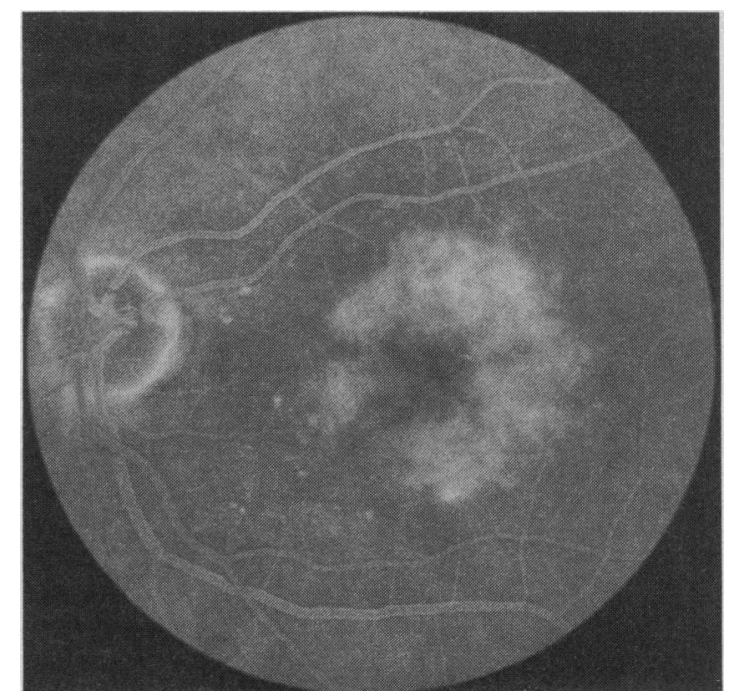

FIG 2-Fluorescein angiogram of the fundus

retinopathy was diagnosed and tamoxifen was discontinued. A total dose of about $73 \mathrm{~g}$ had been given over 60 months. Visual acuity remained unchanged one year after stopping the drug.

\section{Discussion}

Kaiser-Kupfer and Lippman reported on four patients with retinopathy and keratopathy who had received $108-230 \mathrm{~g}$ of tamoxifen over 17-27 months, ${ }^{2}$ and Kaiser-Kupfer $e t$ al have reported the clinical and pathological findings in one of the patients. ${ }^{8}$ McKeown et al reported on a patient who had been given about $90 \mathrm{~g}$ of tamoxifen. ${ }^{3}$ These are relatively high doses, but ocular toxicity with a total dose of less than $10 \mathrm{~g}$ has now been reported. ${ }^{47}$

Our patient was taking $40 \mathrm{mg}$ daily, which is within the recommended dose. Early signs of retinopathy were attributed to exudative maculopathy and age related macular disease. In hindsight it seems more likely that these changes represented tamoxifen toxicity occurring within a few months of treatment.

Tamoxifen is widely prescribed for treating breast cancer. Its use results in "significant reduction in death rate in post mastectomy patients regardless of menopausal status, nodal status or oestrogen receptor content." Recently it has been suggested that five years of tamoxifen therapy after surgery reduces the chance of cancer recurrence. ${ }^{10}$ Tamoxifen is also used for inducing ovulation and in treating some types of male infertility, ${ }^{1}$ but for these indications it is used in relatively small doses.

The mechanism of ocular toxicity with tamoxifen is unresolved. It has been postulated that the cationic amphiphilic nature of tamoxifen allows binding with polar lipids, interfering with their catabolism. ${ }^{8}$ This side effect is not necessarily dose related. ${ }^{1 \cdot 7}$ Retinal toxicity is also caused by drugs like chloroquine that have similar chemical groups.

In view of the widespread use of tamoxifen and the relative rarity of its toxic effect on the retina, ophthalmic screening would be impractical. It is therefore important that all clinicians be aware of this 
potential side effect. Inquiring about drug intake during routine examination, and specifically about long term medications like tamoxifen which patients may forget to mention, could also help early diagnosis. We suggest careful assessment with early referral of patients for ophthalmic examination if visual symptoms develop. The picture of advanced tamoxifen retinal toxicity is pathognomonic. However, opacities in the media may not allow a good view of the fundus and hence make the diagnosis more difficult. Particular caution should be exercised where other potential causes of retinopathy, such as diabetes, are present.

Most importantly, every effort should be made to recognise toxicity before the full characteristic picture of tamoxifen retinopathy with its associated significant and possibly irreversible visual impairment is established.
1 Heel RC, Brogden RN, Speight TM, Avery GS. Tamoxifen: a review of its pharmacological properties and therapeutic use in the treatment of breast cancer. Drugs 1978;16:1-24.

2 Kaiser-Kupfer MI, Lippman ME. Tamoxifen retinopathy. Cancer Treat Rep 1978;62:315-20.

3 McKeown CA, Swartz M, Blom J, Maggiano JM. Tamoxifen retinopathy Brf Ophth 1981;65:177-9.

4 Vinding T, Nielson NV. Retinopathy caused by treatment with tamoxifen in low dosage. Acta Ophthalmol 1983;61:45-50.

5 Griffiths MF. Tamoxifen retinopathy at low dosage. Am $f$ Ophthalmol 1987; 104:185-6.

6 De-Jong-Bosnac M. Ophthalmic complications of low dosage tamoxifen in the treatment of breast carcinoma. Ned Tijdshr Geneeskd 1989;133:514-6.

7 Gerner EW. Ocular toxicity of tamoxifen. Am Ophthalmol 1989;21:420-3.

8 Kaiser-Kupfer MI, Kupfer TC, Rodriques MM. A clinicopathological report. Ophthalmology 1981;88:89-93.

9 Controlled trial of tamoxifen as single adjuvant agent in management of early breast cancer. Analysis at six years by Nolvadex Adjuvant Trial Organisation. Lancet 1985;i:836-9.

10 Adjuvant tamoxifen in the management of operable breast cancer. The Scottish trial. Lancet 1987;ii:171-5.

11 Insler V, Lunenfield B. Infertility: male and female. Edinburgh: Churchill Livingstone, 1986:436,539-41.

(Accepted 27 fuly 1991)

\section{Leading for Health: responses}

\section{Rationing}

\section{Chris Heginbotham}

This is the fourth in a series of articles responding to the questions raised by the BMA's document, "Leading for Health." The document looks well beyond the coming British election and raises questions about health and health care that will be on the agenda of many countries into the next century.

TABLE I - Proportion of gross domestic product $(\%)$ spent on health in various countries in 1980 and 1987

\begin{tabular}{|c|c|c|}
\hline & 1980 & 1987 \\
\hline United States & $9 \cdot 2$ & $11 \cdot 2$ \\
\hline Sweden & $9 \cdot 5$ & $9 \cdot 0$ \\
\hline Canada & $7 \cdot 4$ & $8 \cdot 6$ \\
\hline France & $7 \cdot 6$ & $8 \cdot 6$ \\
\hline Netherlands & $8 \cdot 2$ & $8 \cdot 5$ \\
\hline Austria & $7 \cdot 9$ & $8 \cdot 4$ \\
\hline Germany & $7 \cdot 9$ & $8 \cdot 2$ \\
\hline Iceland & $6 \cdot 4$ & $7 \cdot 8$ \\
\hline Switzerland & $7 \cdot 3$ & $7 \cdot 7$ \\
\hline Luxembourg & $6 \cdot 8$ & $7 \cdot 5$ \\
\hline Norway & $6 \cdot 6$ & $7 \cdot 5$ \\
\hline Finland & 6.5 & $7 \cdot 4$ \\
\hline Belgium & $6 \cdot 6$ & $7 \cdot 2$ \\
\hline Australia & $6 \cdot 5$ & $7 \cdot 1$ \\
\hline Italy & $6 \cdot 8$ & 6.9 \\
\hline New Zealand & $7 \cdot 2$ & 6.9 \\
\hline Japan & $6 \cdot 4$ & $6 \cdot 8$ \\
\hline Portugal & $5 \cdot 9$ & $6 \cdot 4$ \\
\hline United Kingdom & $5 \cdot 8$ & $6 \cdot 1$ \\
\hline Spain & $5 \cdot 9$ & $6 \cdot 0$ \\
\hline Denmark & $6 \cdot 8$ & $6 \cdot 0$ \\
\hline Greece & $4 \cdot 3$ & $5 \cdot 3$ \\
\hline Mean & $7 \cdot 0$ & $7 \cdot 5$ \\
\hline
\end{tabular}

Source: OECD, 1987

King's Fund College, London W2 4HS

Chris Heginbotham, MA, fellow in health services management

BMF 1992;304:496-9
All health services ration health care. This truism hides a variety of forms. The United Kingdom health service rations through non-availability, primary care gatekeeping, and waiting lists. The United States service rations partly by income and partly by insurance companies funding either a core group of services or by placing treatment and lifetime caps on the cost of an individual patient's care.

Social insurance schemes such as that in Germany ration through protocol agreements with doctors and by payment for a basic service to which the individual consumer can add by additional contribution. Central and eastern European countries have until recently rationed according to the degree of "cunning" that the individual consumer was able to bring - the key skill was knowing the way around the system and who to bribe. Although that is now changing, old habits die hard.

These main features of each system appear in every system to some degree. The NHS is not immune to abuse; sometimes access to the best possible careeven any care - is by having the right contacts. What the United Kingdom does not have, at least explicitly, is a constrained group of core services, or some form of treatment or lifetime cap on the amount that can be spent on any individual. And the United Kingdom has avoided the worst excesses of the American system. Latest figures put the number of uninsured people in the United States at between 35 million and 37 million, 'some of whom, it is true, obtain Medicaid benefit but many of whom do not. Even those who are insured may have significant limits placed on the benefits that they may receive for the premiums that they can afford.

The BMA's document Leading for Health: a BMA Agenda for Health ${ }^{2}$ sets out four questions about rationing: Is rationing inevitable? Should rationing be explicit? How might rationing be achieved? Who will make the decisions on rationing? In this article I examine these four questions.

\section{Is rationing inevitable?}

The short answer to this first question is yes. Empirical evidence from all health services suggests that rationing takes place either covertly or explicitly and always has done. Beveridge's and Bevan's hope that comprehensive health care free at the point of delivery funded out of taxation would eventually become self levelling was an unattainable dream.

Improvements in access, pharmaceutical innovations, and high technology medicine have steadily increased the cost of health care at an inflation rate well beyond the retail price index. In all countries in the Organisation for Economic Cooperation and Development the proportion of gross domestic product spent on health has increased steadily, though at a differential rate. The United States now spends $12 \%$ of its gross domestic product per capita on health care, and even with cost containment measures that figure is likely to reach at least $15 \%$ by the year 2000 , possibly sooner. ${ }^{3}$ Table I shows the wide differentials between countries, though these figures must be compared with those in table II for general purchasing power parities (PPPs) and health care purchasing parities - these show that the United Kingdom is not as far behind the United States or Germany as the broad gross domestic product figures may suggest.

None the less the most striking feature of the health care policy debate, particularly during the late 1980 s, has been the desire to find effective cost containment measures. The United States has gone through a series of organisational developments with the introduction of health maintenance organisations, preferred provider organisations, and other forms of "managed care." Prospective, concurrent, and retrospective utilisation review is now required of provider organisations by many insurance companies. Clinical audit has become a necessity. Worries about escalating costs led to the development of diagnostic related groups, which are now used for the funding of Medicaid and Medicare (for indigent poor and elderly people respectively) by the federal government.

None of these methods seems to be working, perhaps because of the pluralism inherent in the American system, the litigious nature of society, and the demand by American people for the latest diagnostic or technological intervention. Even with some cost containment through reimbursement for diagnostic related groups, many states, of which Oregon is only the most famous, are looking for other methods of resource allocation.

All forecasts of health care expenditure show an ever expanding demand and exponentially increasing cost 